\title{
A STUDY ON BEHAVIOUR OF OUTRIGGER SYSTEM ON HIGH RISE STEEL STRUCTURE BY VARYING OUTRIGGER DEPTH
}

\author{
Srinivas Suresh Kogilgeri ${ }^{1}$, Beryl Shanthapriya ${ }^{2}$ \\ ${ }^{1}$ Post Graduate Student, Department of Civil Engineering, The Oxford College of Engineering, Bangalore \\ ${ }^{2}$ Assistant Professor, Department of Civil Engineering, The Oxford College of Engineering, Bangalore
}

\begin{abstract}
The outrigger system is one of the most efficient system used for high rise structures to resist lateral forces. In the present study an attempt has been made to study the static and dynamic behavior of the outrigger structural system on steel structure by reducing the depth of outrigger.5X5 bay 40 story 3D steel structures is modeled in ETABS v2013 software. Steel structure with central core and steel structure with outrigger structural system of varied depth of outrigger are compared. The depth of the outrigger is reduced to $2 / 3^{\text {rd }}$ and $1 / 3^{\text {rd }}$ of the story height along with the full story height. The depth of the belt-truss is equal to the height of the typical story and maintained same in all the structures. The key parameters discussed in this paper include lateral deflection and storey drift. From the analysis results it has been found that the comparative performance of outrigger with depth of full storey height and decreased depth shows minor difference in resistance towards lateral loads.
\end{abstract}

Keywords: Outrigger system, Lateral Displacement, Inter story drift

\section{INTRODUCTION}

The outrigger structural system is one of the horizontal load resisting systems. In this system the belt truss ties all the external columns on the periphery of the structure and the outriggers connect these belt trusses to the central core of the structure thus restraining the exterior columns from rotation. This system is functionally efficient as there is a free floor space between the central core and the exterior columns.

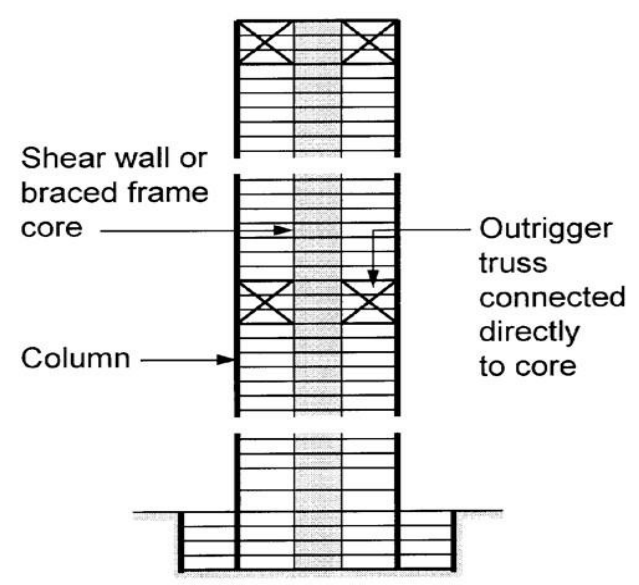

Fig.1 outrigger structural system

\subsection{Advantages and Disadvantages of Outriggers}

\section{Advantages}

- Outrigger system can be incorporated into steel, concrete or composite structures.
- $\quad$ Rigid frame connections can be avoided on the exterior frame of the structures, bringing out economies.

- Considerable reduction or complete elimination in the net tension forces in the columns and foundations.

- The external column spacing is not governed by structural consideration and can easily spaced from aesthetic and functional perspective.

\section{Disadvantages}

- Outrigger systems interfere with the occupiable and rentable space.

- Connection at the interface between core and foundation is expensive and involves intensive work.

- Labour intensive and expensive rock anchors are required alternative to simple spread footing.

- Expensive foundations solely required to resist overturning moments.

\subsection{Objective}

Outrigger structural system increases the stiffness and makes the structural form very efficient under lateral loading. Outrigger reduces the overturning moment on the core and transfer the reduced moment to columns outside the core by the action of tension-compression coupled, which take advantage of the increase moment arm between these columns. The present thesis is aimed at investigating comparative lateral load resistance between structure with central braced core and structure with outrigger system. Here the depth of the outrigger is reduced to different depths in each model and analyzed and then compared. The depth of the belt-truss is equal to height of the typical story and maintained same in all the models. The structure is assumed to be located in Bangalore. The structure is analyzed in ETABS v2013. 


\section{MODELLING AND ANALYSIS}

The structure is assumed to be located at Bangalore. For analysis, 40 story steel structure is considered. The plan dimension of the structure is $30 \mathrm{X} 30 \mathrm{~m}$. typical story height is $3.2 \mathrm{~m}$, overall structure height is $128 \mathrm{~m}$. The structure is symmetrical about both $\mathrm{X} \& \mathrm{Y}$ axis. Chevron (inverted v) bracings is used for both core and outrigger system. The structure is modeled as without infill. Material of concrete grade is M20. Slab thickness is $150 \mathrm{~mm}$. column size changes at each 10 story. Modal damping of $2 \%$ is considered. To enable diaphragm action, diaphragm is assigned at each level. The structure is assumed to be fixed at the ground level. The depth of the outrigger is reduced to $2 / 3^{\text {rd }}$ and $1 / 3^{\text {rd }}$ of the story height along with the full depth. The depth of the belt-truss is maintained same in all the structures i.e. height of typical story. The structure with braced core is compared with structures of varied depth of outrigger. Initially the structure with braced core is compared with the structure with cap truss only, then additional outrigger and belt truss is added at the $0.5 \mathrm{H}$ of the structure and then compared.

Equivalent static method and Response spectrum method are used in the analysis as per IS-1893 (Part 1). The structure is subjected to wind load as per IS-875 (Part 3).

\subsection{Details of Model}

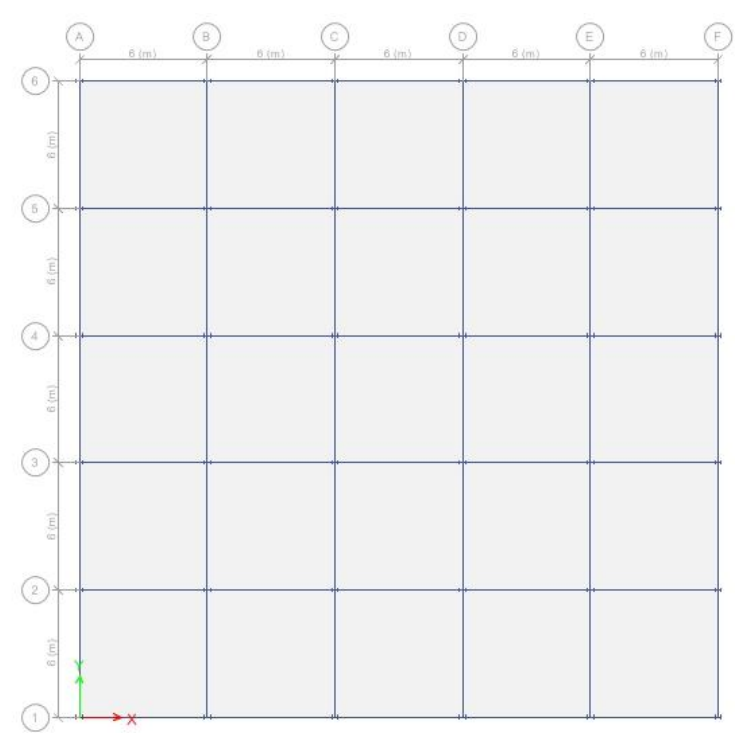

Fig.2 Plan of structure

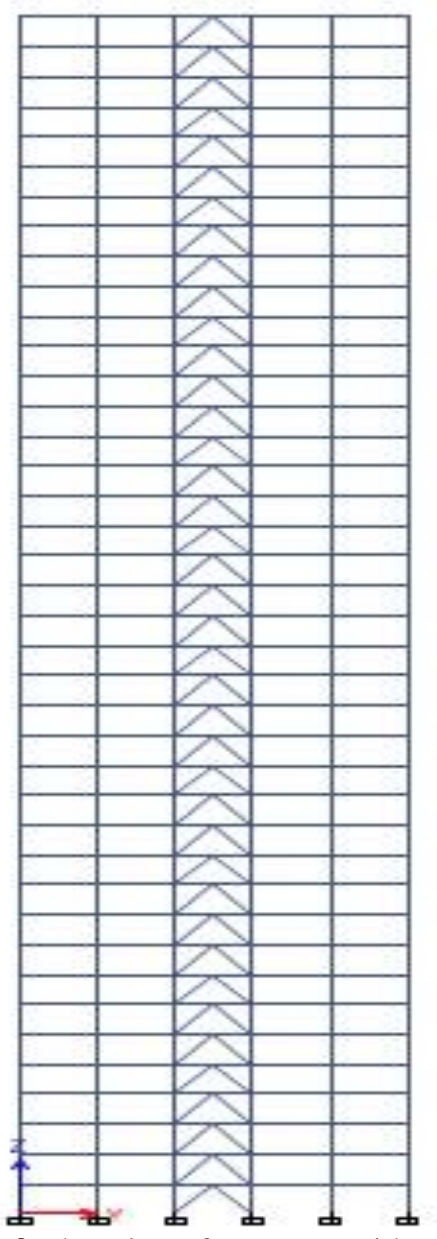

Fig.3 Elevation of structure with core

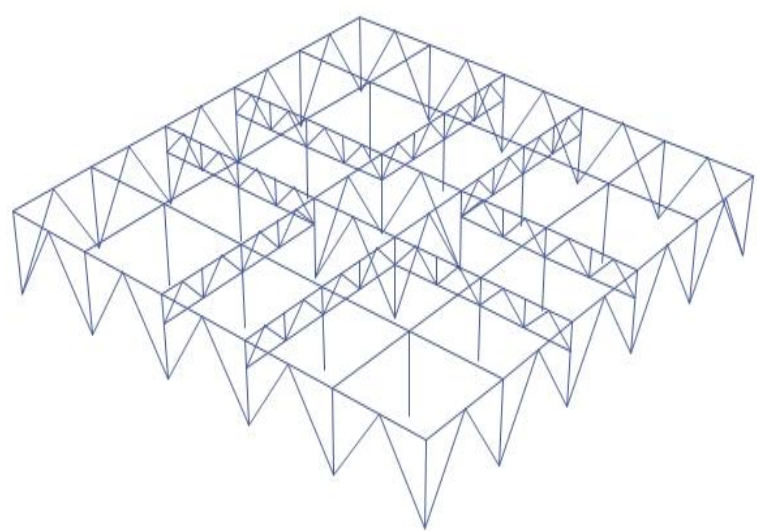

Fig.4 3D view of typical story with outrigger depth $1 / 3^{\text {rd }}$ of story height 

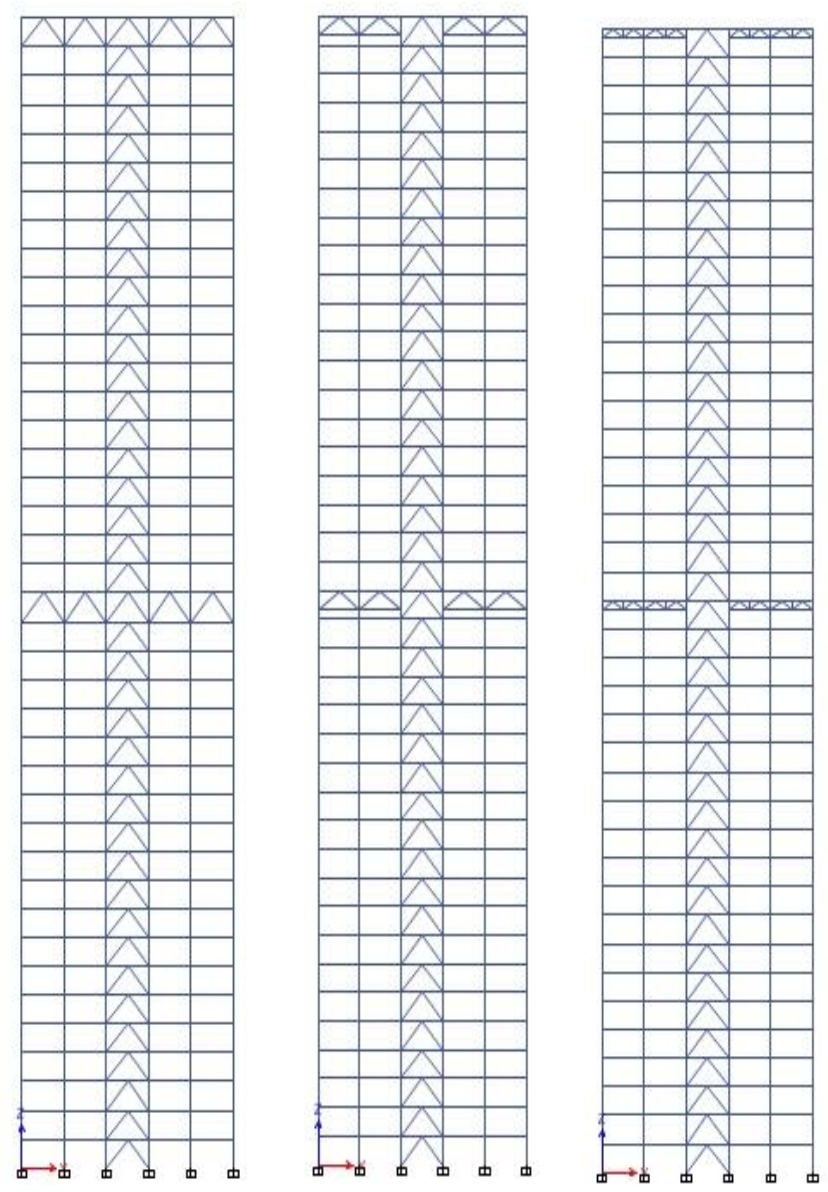

Fig.5 Elevation of structure with outriggers

\subsection{Material Properties}

Concrete: Grade M-20, Density 2458.538 Kg/m3, Young's Modulus 22360.68 Mpa, Shear Modulus 9316.95 Mpa, Poisson's Ratio 0.2.

Steel: Fe 250, Density $7849.047 \mathrm{Kg} / \mathrm{m} 3$, Young's Modulus 210000 Mpa, Shear Modulus 80769.23 Mpa, Poisson's Ratio 0.3.

\subsection{Section Properties}

Table-1: Section properties

\begin{tabular}{|l|l|l|l|}
\hline Story level & Column Size & Beam Size & Bracing Size \\
\hline G+10 & ISMB 600 & ISMB 550 & \multirow{2}{*}{ ISA } \\
\cline { 1 - 3 } $11-20$ & ISMB 500 & ISMB 450 & ISA $00 X 150 X 15$ \\
\hline $21-30$ & ISMB 400 & ISMB 350 & \\
\hline $31-40$ & ISMB 300 & ISMB 250 & \\
\hline
\end{tabular}

\section{RESULTS AND DISCUSSIONS}

\subsection{Case 1: Comparison of Structure with Braced} Core and Structure with Outrigger Depth of Full

\section{Story Height}

\subsubsection{Displacement}

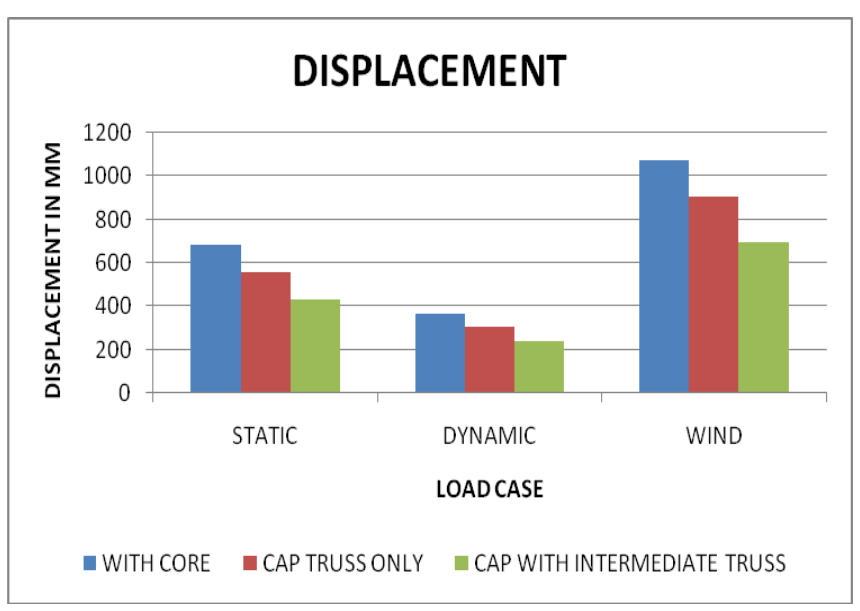

\section{Story Drift}

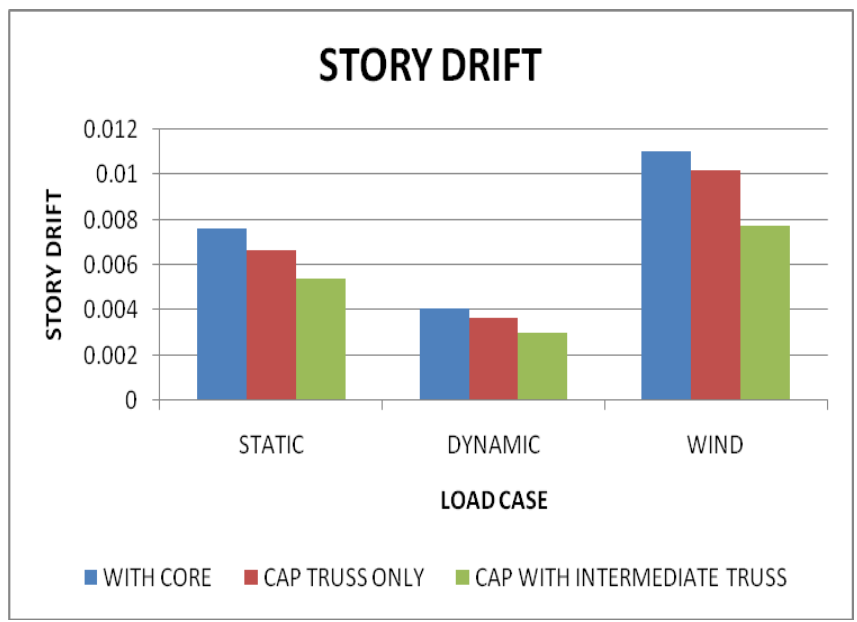

CT- Cap Truss, CT + IT- Cap With Intermediate Truss

Table-2: Percentage Reduction Case 1

\begin{tabular}{|l|l|l|l|l|}
\hline \multirow{2}{*}{ LOAD } & \multicolumn{2}{|l|}{$\begin{array}{l}\text { DISPLACEMENT } \\
\text { \% REDUCTION }\end{array}$} & \multicolumn{2}{l|}{$\begin{array}{l}\text { STORY DRIFT } \\
\text { \% REDUCTION }\end{array}$} \\
\cline { 2 - 5 } & CT & CT + IT & CT & CT + IT \\
\hline STATIC & 18.54 & 36.96 & 12.54 & 29.03 \\
\hline DYNAMIC & 16.30 & 34.51 & 10.19 & 27.19 \\
\hline WIND & 15.72 & 35.06 & 15.72 & 30.10 \\
\hline
\end{tabular}

When the structure with outrigger depth of full story height was analyzed the displacement and story drift were reduced up-to $18.54 \%$ and $15.72 \%$ for structure with single cap truss and $36.96 \%$ and $30.10 \%$ when the additional outrigger truss is provided at the $0.5 \mathrm{H}$ of the structure. 
3.2 Case 2: Comparison of Structure with Core and Structure with Outrigger Depth of $2 / 3^{\text {rd }}$ of Story Height

\subsubsection{Displacement}

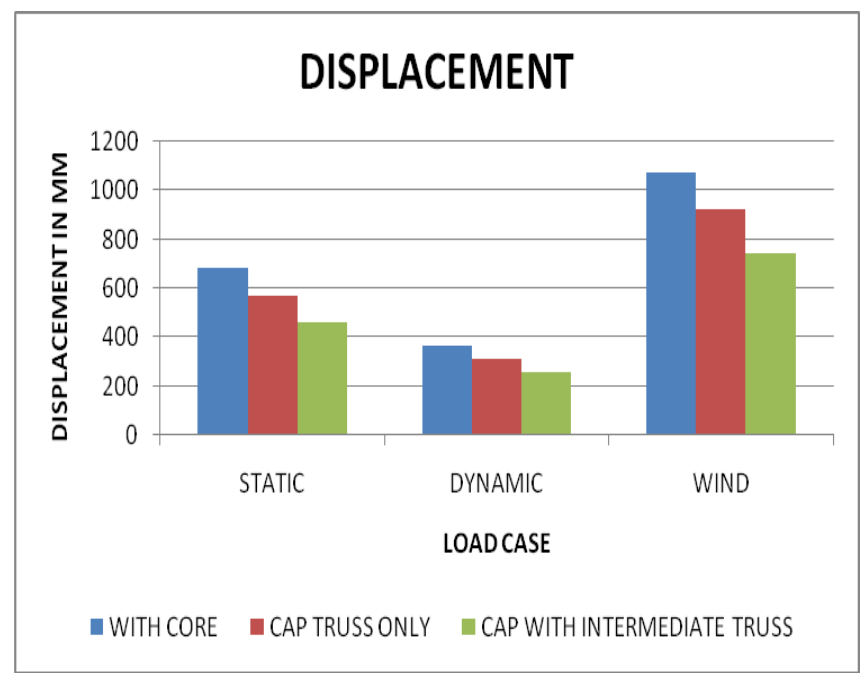

\subsubsection{Story Drift}

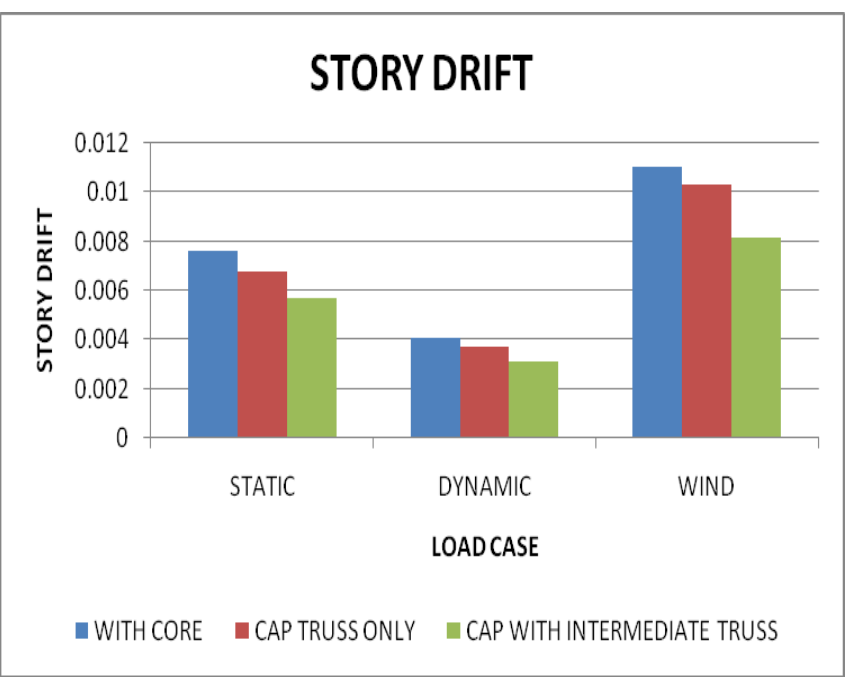

CT- Cap Truss, CT + IT- Cap With Intermediate Truss

Table-3: Percentage Reduction Case 2

\begin{tabular}{|l|l|l|l|l|}
\hline \multirow{2}{*}{ LOAD } & \multicolumn{2}{|l|}{$\begin{array}{l}\text { DISPLACEMENT } \\
\text { \% REDUCTION }\end{array}$} & \multicolumn{2}{l|}{$\begin{array}{l}\text { STORY DRIFT } \\
\text { \% REDUCTION }\end{array}$} \\
\cline { 2 - 5 } & CT & CT + IT & CT & CT + IT \\
\hline STATIC & 16.78 & 32.26 & 11.43 & 25.21 \\
\hline DYNAMIC & 14.67 & 30.16 & 9.38 & 23.37 \\
\hline WIND & 14.13 & 30.60 & 6.63 & 25.76 \\
\hline
\end{tabular}

When the structure with outrigger depth $2 / 3^{\text {rd }}$ of story height was analyzed, the displacement and story drift were reduced up-to $16.78 \%$ and $11.43 \%$ for structure with single cap truss and $32.26 \%$ and $25.76 \%$ when the additional outrigger truss is provided at the $0.5 \mathrm{H}$ of the structure.
3.3 Case 3: Comparison of Structure with Core and Structure with Outrigger Depth of $1 / 3^{\text {rd }}$ of Story Height

\subsubsection{Displacement}

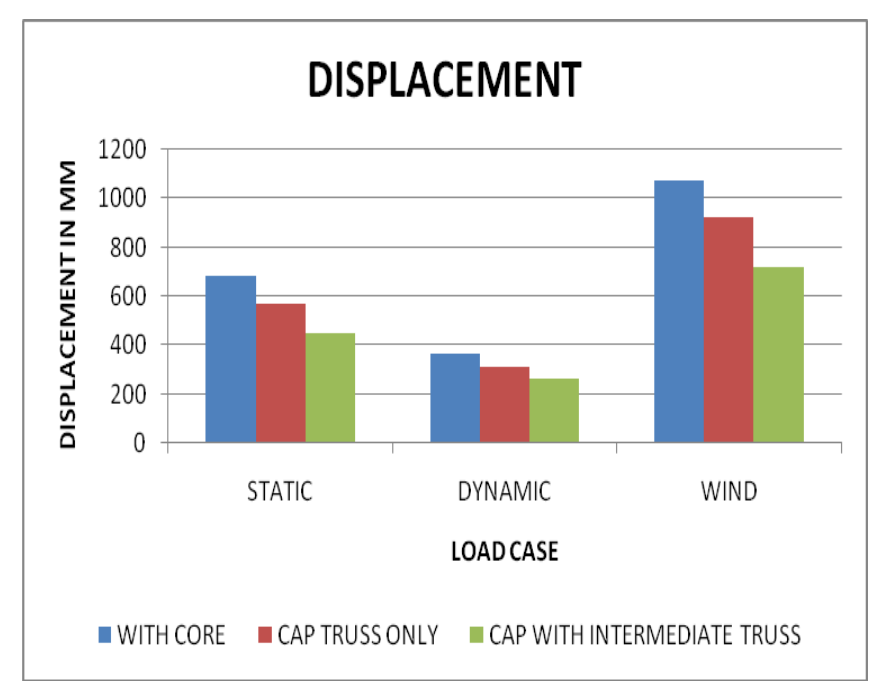

\subsubsection{Story Drift}

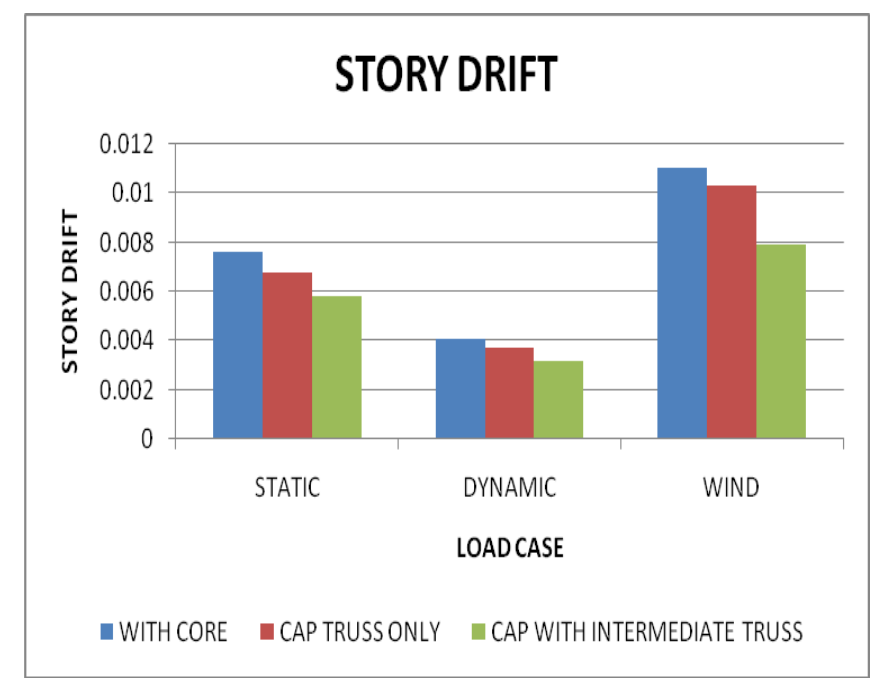

Table-4: Percentage Reduction Case 3

\begin{tabular}{|l|l|l|l|l|}
\hline \multirow{2}{*}{ LOAD } & \multicolumn{2}{|l|}{$\begin{array}{l}\text { DISPLACEMENT } \\
\% \text { REDUCTION }\end{array}$} & \multicolumn{2}{l|}{$\begin{array}{l}\text { STORY DRIFT } \\
\% \text { REDUCTION }\end{array}$} \\
\cline { 2 - 5 } & CT & CT + IT & CT & CT + IT \\
\hline STATIC & 16.49 & 30.36 & 11.25 & 23.58 \\
\hline DYNAMIC & 14.40 & 28.26 & 9.23 & 21.82 \\
\hline WIND & 13.95 & 32.74 & 6.49 & 28.23 \\
\hline
\end{tabular}

CT- Cap Truss, CT + IT- Cap With Intermediate Truss

When the structure with outrigger depth $1 / 3^{\text {rd }}$ of story height was analyzed and compared with the structure having braced core the displacement and story drift were reduced up-to $16.49 \%$ and $11.25 \%$ for structure with single cap truss and $34.74 \%$ and $28.23 \%$ when the additional outrigger truss is provided at the $0.5 \mathrm{H}$ of the structure. 


\section{CONCLUSION}

1) The use of outrigger structural system increases the stiffness of the structure by connecting the building core to the distant column and makes the whole system to act as a single unit in resisting the lateral load.

2) The Structures with cap truss and an additional intermediate truss placed at $0.5 \mathrm{H}$ shows $16 \%$ increased performance, when compared with the structures with only cap truss.

3) When we consider the criterion variable depth, the decrease in the depth of the outrigger to $2 / 3^{\text {rd }}$ of the story height reduces the percentage reduction of lateral displacement and story drift up-to $4 \%-5 \%$ in comparison with outrigger depth of full story height.

4) Further decrease in the depth of the outrigger to $1 / 3^{\text {rd }}$ of the story height reduces the percentage reduction of lateral displacement and story drift up-to $6 \%-7 \%$ in comparison with outrigger depth of full story height.

5) Comparative performance of outrigger with depth of full storey height \& decreased depth shows minor difference.

\section{REFERENCES}

[1] Junais Ahmed A.K., Yamini Sreevalli (2014) "Application of Outrigger in Slender High Rishe Buildings to Reduce Fundamental Time Period".

[2] K.K.Sangle, K.M.Bajoria, V.Mhalungkar (2012) “ Seismic Analysis of High Rise Steel Frame with and Without Bracing.

[3] Kiran Kamath, Avinash A.R., Sandesh Upadhyaya K. "A Study on the Performance of Multi-Outrigger Structure Subjected to Seismic Loads.

[4] M.R.Jahanshani, R.Rahgozar (2013) "Optimim Location of Outrigger-Belt Truss in tall buildings Based on Maximation of Belt Truss Strain Energy.

[5] N.Hearth, N.Haritos, T.Ngo, P.Mendis (2009) "Behaviour of Outrigger Beams in High rise Buildings under Earthquake Loads.

[6] Z.Bayati, M.Mahdikhani, A.Rahaei (2008) "Optimized use of Multi-Outriggers System to Stiffen tall Buildings.

[7] P.M.B.Raj Kiran Nanduri, B.Suresh, MD.Ihtesham Hussain (2013) "Optimum Position of Outrigger System for High-Rise Reinforced Concrete buildings under Wind and Earthquake Loadings".

[8] Kiran Kamath, N.Divya, Asha U Rao (2012) “A Study on Static and Dynamic Behavior of Outrigger Structural System for Tall Buildings.

[9] Gerasimidis S (2009) "Optimum Outrigger Location of High Rise Steel buildings for wind loading".

[10] Shivacharan K, Chandrakala S, Karthik N M (2015) "Optimum Position of Outrigger System for Tall Vertical irregularity Structures".

[11] Wind loads (IS: 875 PART 3)-1987.

[12] Earthquake load (IS: PART) - 2002. 